\title{
Dominação e Indiferença na Teoria Crítica de Gabriel Cohn
}

\section{José Maurício Domingues}

Instituto de Estudos Sociais e Políticos (IESP), da Universidade do Estado do Rio de Janeiro (UERJ). Rio de Janeiro, RJ, Brasil (e-mail: jmdomingues@iesp.uerj.br).

\section{INTRODUÇÃO}

$\mathrm{O}$ Brasil é um país cujos cientistas sociais tendem a olhar como se fosse exclusivo, como se houvesse uma demanda de conhecimento de sua realidade que se pusesse acima de tudo e mesmo excluísse, na prática, que o pensamento social se ocupasse de outras dimensões e de outras paragens. $\mathrm{O}$ estudo social da realidade entre nós tem padecido bastante deste viés "nacionalista metodológico". Não se trata de tara nossa apenas, mas, sim, de problema que acomete os países periféricos de modo bastante geral: sua situação não-central parece levar sua intelectualidade a ocupar-se de sua especificidade (contrastada de algum modo com o Ocidente) e a uma recusa a enfrentar temas mais gerais ou universais - caso em que é farta a América Latina, para ficar somente em nosso subcontinente (cf. Zea, 1976). Aliado ao tamanho do país, esse viés particularista faz com que, afinal de contas, o que parece interessar realmente seja a nossa "civilização brasileira". As teorias são assim, de modo geral, importadas como se compra pacotes de inovação tecnológica que nos mantêm na dependência das grandes empresas internacionais. Afinal, por que gastar tempo e intelecto com coisas que fogem à nossa esfera de possibilidades efetivas? Para que organizar um debate que tenha como foco essas questões e desenvolvê-las de maneira relativamente independente entre nós?

DADOS - Revista de Ciências Sociais, Rio de Janeiro, vol. 54, nº3, 2011, pp. 429 a 448. 
Gabriel Cohn desafia essa convencional prática nacional. Formado na tradição sociológica da Universidade de São Paulo (USP), onde Florestan Fernandes ([1958] 1977), ainda que com intenções meramente pragmáticas, reiterava essa perspectiva ao reservar aos centros estrangeiros a tarefa de desenvolver a teoria sociológica, Cohn ousou criticamente - como assinala livro recentemente relançado em sua homenagem (Waizbort, [1998] 2008) - pensar a teoria entre nós. Até há pouco em razoável solidão. Não que o Brasil não lhe interessasse ou não interesse. Ao contrário, no Centro de Sociologia da Indústria e do Trabalho (CESIT), dirigido por Fernandes, iniciou uma trajetória de preocupação com temas nacionais relevantes, como atesta sua tese de mestrado sobre a Petrobras (Cohn, 1968b) e estudos vários posteriores. Mas não foi aí que concentrou seus esforços e seu pensamento, mas, sim, na teoria social e sociológica de corte crítico, com fortes laços com a Escola de Frankfurt.

Em que então consiste teoria para ele? A pergunta não é de simples resposta, pois Cohn não possui uma obra realmente sistemática, nem é seu estilo necessariamente direto e afirmativo, preferindo muitas vezes lançar questões aos leitores mediante o estudo de certos autores, com as respostas, com frequência, mantendo-se implícitas. Ele nos brindou com textos sobre temas metodológicos, dos quais mesmo os mais antigos se mantêm atuais. Este é o caso de sua participação em debate acerca da relação entre teoria e empiria (Cohn, 1968a), em que, de resto, rompia de maneira indireta, mas decerto nem por isso menos consciente, com o privilégio que Fernandes atribuía à pesquisa empírica no Brasil e, inclusive, com o que mais tarde veio a definir como o "ecletismo bem-temperado" do mestre (Cohn, 1986), ao reivindicar o rigor da teoria como organizadora de uma totalidade conceitual, sem prejuízo da pesquisa empírica. Em outras ocasiões abordou os tipos ideais (Cohn, 1978, 2000a) ou trouxe à cena a categoria adorniana da mediação para dar conta da questão da totalidade no que tange ao estudo da política contemporânea (Cohn, 1987). E enfrentou as teorias de autores diversos, desde Weber, Simmel, Durkheim e Tocqueville, a Habermas e Luhmann, passando, é claro, por seus preferidos, Adorno e Horkheimer (Cohn, 1978, 1986, 1987, 1990, 1993, 1997, 1998c, 1999, 2000a, 2000b). Curiosamente, Marx, que ele reputa o maior de todos (Cohn, 2006b:122), pouco recebeu atenção direta em seus escritos, embora em particular, mas não apenas, pela mediação de Adorno (ver especialmente Cohn, 1973:126-128) ele esteja presente em muitos momentos. Ademais, vários autores vêm se tornando melhor conhecidos 
no Brasil por sua influência e pela edição de seus escritos, casos notadamente de Weber e Adorno, até o presente momento inclusive.

Minha hipótese é que existe um tema-chave nos textos de Cohn que, às vezes mais explícito, às vezes de forma mais implícita, organiza boa parte de sua reflexão. Trata-se da questão da dominação. Poder-se-ia supor que Weber lhe proporcionara esta ideia básica, mas creio que isso não é verdadeiro. Na realidade, ao contrário, foi esta chave que lhe permitiu fazer uma leitura inovadora - e, a meu ver, sem par em termos de clareza, precisão e originalidade - da metodologia weberiana, com uma apropriação da obra do sociólogo alemão pelo viés da crítica à modernidade, no sentido forte do termo. É isto que se trata de demonstrar nas próximas páginas. Vale notar ainda que a ideia de "pluralismo" segue lateralmente à de dominação nos escritos de Cohn, vindo a assumir, mais recentemente, destaque em suas reflexões, relida pelo prisma da diferença.

\section{A CENTRALIDADE DAS RELAÇÕES DE DOMINAÇÃO}

A entrada forte de Cohn no debate intelectual brasileiro foi, ao mesmo tempo, sua estreia em grande estilo na área da teoria sociológica, pela via da discussão da teoria da comunicação e da indústria cultural. Trata-se de uma versão revisada de sua tese de doutorado, Sociologia da comunicação. Teoria e ideologia, publicada em 1973. E o compromisso com a crítica, em particular de uma divisão e nomenclatura que estavam bastante na moda - o que não quer dizer em absoluto que tenham desaparecido-, se põe de maneira central nos fundamentos de seu argumento conceitual. "Massa" e "elite" eram então dois termos-chave na discussão sobre a cultura. Cohn deixa claro que a ideia de "massa" (e seu correlato, "multidão") tinha origem na reação conservadora do século XIX à Revolução Francesa. Em Le Bon ela era fundamental; Tocqueville, Mill e Hegel reafirmaram o viés negativo dessa perspectiva e sua expressão como "opinião pública" massificada, isto é, sem espaço para a individualidade racional; e a filosofia e as ciências sociais posteriormente absorveram, conscientes ou não de suas origens, tal noção em seu aparato discursivo, como se vê em Durkheim e Arendt (Weber mantendo-se aí curiosamente ausente). Isso teve grande impacto na teoria da comunicação, inclusive nas ideias defendidas por autores como Blumer. A irracionalidade das massas era o ponto crucial do diagnóstico altamente negativo que essa linha de pensamento tão influente apresentava (Cohn, 1973:17ss, 45-51, 63ss). A ela se contrapunha o con- 
ceito de "elite", que seria compartilhado, variações não obstante, por autores como Mosca e Mannheim, e inclusive por Wright Mills (que se perderia ao acabar tendo que supor a existência de uma "massa" para tentar denunciar o poder de supostas "elites"). Mas Cohn é ácido quanto a tal construção:

[...] o problema não é o da simples presença de minorias dominantes, mas da legitimação de seu domínio enquanto "elites". Resta saber se uma noção tão obviamente construída pelos interessados, para justificar sua posição de mando na sociedade, pode ser considerada apta a converter-se em conceito científico. Na realidade, a noção de elite representa a quase exata contrapartida daquela de massa. Trata-se de construção de caráter ideológico, no sentido mais imediato do termo. É a contrapartida "quase exata" porque o estatuto histórico dessas noções não é equivalente. Ambas são produzidas na mesma área da sociedade: justamente aquela ocupada pelas "elites". (ibidem:30, ênfases do original)

Assim, se em um primeiro momento a ideia de público e opinião serviu à burguesia ascendente para desafiar o Absolutismo e conquistar espaços sociais e políticos, à medida que os setores populares se faziam mais presentes uma distinção que buscava garantir a legitimidade do domínio de tais "elites" emergiu - como uma "ficção política negativa": a "massa" - para defender a nova forma de dominação, o poder "já conquistado", em um sentido "restritivo". A própria ideia de opinião pública se transmuda, desde Hume, na verdade, e mais claramente a partir do utilitarismo de Bentham: ela se referirá doravante a uma forma de "controle social" por parte dos detentores do poder, antes que à expressão de uma racionalidade livremente expressa na esfera pública. Em Mills, ademais, o "público" já se dissocia e se opõe à "massa", ao passo que os intelectuais alemães reivindicariam uma liderança da elite para a formação do juízo estético das classes médias, excluídas da possibilidade de fruição dos bens culturais as camadas inferiores. E, de Tocqueville a Arendt, a atomização dos indivíduos perante um Estado todo-poderoso vai ganhando pouco a pouco preeminência (ibidem:41-42, 58-62).

Assinale-se, desde logo, que a narrativa e conceitualização de Cohn, a despeito de seu formato mais limitado, apresenta uma diferença significativa em relação à hoje famosa teoria de Habermas ([1962] 1984) a respeito da emergência da "esfera pública". Este autor via seu apogeu no século XIX, sem de fato tematizar seu caráter burguês excludente e 
supostamente racional-consensual, o que lhe valeu inúmeras críticas (ver Eder, 1985 e 2006), e sem pôr em tela a questão da dominação, que surgiria de forma específica, isto é, sistêmica, somente no século XX. Em contrapartida, Cohn é bastante mais crítico ao assinalar que as ideias de comunicação, público e opinião vêm, em seus primórdios mesmo, contaminadas pelo sistema burguês de dominação e pelo ranço conservador que visava a excluir as "massas" do direito legítimo de participar das instituições modernas em construção. É que em Habermas as ideias de dominação e conflito estão fundamentalmente ausentes, assim como classes e agência coletiva em sentido forte, ao contrário do que ocorre com Cohn, embora, ao menos formalmente, mais adiante Habermas (1992) recusasse uma concepção elitista da democracia. O que não poderia deixar mesmo de ser o caso, pois, como Cohn (1973:70) observa em relação a Kornhauser, um dos principais teóricos da sociedade de massas (e do chamado "totalitarismo"), é preciso dar-se conta de que "[...] uma teoria que toma como noções centrais as de 'elite' e 'massa' simplesmente não pode ser democrática, visto que suas categorias centrais de análise são inteiramente conservadoras e 'aristocráticas', seja como for o modo em que se articulam no discurso". Obviamente, Cohn não quer dizer com isso que qualquer autor que utilize essa conceituação - e hoje são muitos os que o fazem, ao menos no que concerne às "elites" - seja antidemocrático, conservador ou algo semelhante. Antes, nos convida a examinar, criticamente, o significado profundo de noções que podem, à primeira vista, parecer inocentes, encontrando abrigo até mesmo em autores inconformistas, como no caso de Wright Mills.

Vale notar ainda que Cohn exime Freud e a Escola de Frankfurt, isto é, Adorno, Horkheimer e Marcuse, de responsabilidade no uso dessas categorias. Em Freud, contrariamente à usual assimilação de sua obra à vertente representada por LeBon, não obstante elementos conservadores expressivos em sua concepção de modo geral, Cohn vai descobrir na ideia de "massa" uma maneira quase sociológica, ainda que obviamente estruturada pelas teses da psicanálise, de tratar noções como "grupo" e "instituição", com ênfase no papel que cumpre o "Ego ideal" como argamassa, por vezes problemática sem dúvida, da solidariedade social. Destaca aí, mais uma vez, a questão da dominação na relação entre "líder" e "massa" (ibidem:24-26). No que se refere a Adorno e Horkheimer, rejeita qualquer identificação de suas ideias com a corrente predominante da teoria da sociedade de massas ${ }^{1}$. Se empiricamente, admite, a referência à "massa" pode ser encontrada de passa- 
gem na obra daqueles autores como "agregado de indivíduos atomizados" - noção que, deve-se frisar, de resto não compartilha -, teoricamente para eles se trataria de destacar, de novo, o tema da dominação, pois veriam a "massa" como "produto social do aproveitamento racional dos elementos irracionais disponíveis" (ibidem:27). Mais ainda, ao recuperar as últimas obras de Adorno, em que a teoria da "racionalização" de Weber - que resultaria, em larga medida, na ideia de "sociedade administrada" - cede à embocadura anticapitalista da teoria de Marx sobre "fetichismo da mercadoria", Cohn (ibidem:124-128, 129-132ss) reitera a questão da dominação. Ele aponta o papel das ideologias, da "falsa consciência" e, em particular, das classes sociais, destacando a esfera da produção em relação à do consumo no que tange àquilo que Adorno trataria como a "indústria cultural". Isso o levaria, de forma um tanto obscura, pois se resume a uma promessa a ser posteriormente desenvolvida, à tese de que o conceito de mensagem forneceria o núcleo teórico e metodológico de uma sociologia da comunicação (ibidem:159, 161-162) ${ }^{2}$.

Em que medida isso se manteria nos trabalhos posteriores de Cohn? Não provocaria a introdução da obra de Weber uma inflexão em seu pensamento, afastando-o de uma construção crítica tão cortante como a manifestada nesta sua primeira grande obra? De modo algum. Pois o que emerge de sua leitura em Crítica e resignação. Fundamentos da Sociologia de Max Weber reitera aqueles temas. Bastante marcada pela concepção de Fleischmann ([1964] 1977; Cohn, 1979:esp. cap. 3), que ele mesmo fez publicar anteriormente em português, ela traz para a linha de frente precisamente o conceito de dominação, que emerge em Weber em grande medida sob a influência, embora não exclusiva e muito menos absoluta, de Nietzsche. Cohn tratará o vocábulo Herrschaft como dominação mesmo, sem meias-palavras, confirmando a sua dura carga realista, vendo o poder não como mera autorização legítima e, sim, como a capacidade de fazer com que outrem se comporte de acordo com a vontade e o comando (Behfel) daquele que se encontra em posição hierárquica superior, ainda que com uma roupagem hermenêutica que de alguma forma justifique essa capacidade diferencial, do que derivam importantes consequências metodológicas e éticas. A própria racionalização, ainda que Weber jamais o explicite, é entendida como, pelo menos em parte, um resultado da dominação, porquanto a probabilidade (ou "chance") de uma ação ter curso se alicerça na permanência das condições sociais; esta, por seu turno, operaria como "um índice da presença e da eficácia do processo de dominação/legiti- 
mação, na medida em que é nesse processo que encontramos a forte conversão de linhas de ação em condutas cotidianas [...]", para além da mera rotina. E mais, a dominação permite medir inclusive o "grau" de racionalização das ações, pois é ela que faz com que aquela torne estas "plenamente" previsíveis (Cohn, 1979:90), sem que interessassem a Weber, argumenta Cohn (ibidem:82), as "vivências" do sujeito em relação a sua personalidade, mas, sim, sua "experiência" na relação com outros agentes, em princípio livres e capazes de impacto causal, mas submetidos a relações de poder que estruturam a realidade e a própria leitura que dela podemos fazer. Sujeito e dominação são, assim, "categorias fundamentais" no esquema (analítico) weberiano e ganham destaque na interpretação que vamos reconstruindo (ibidem:138).

Contra Bendix, Cohn explicitamente recusa a identificação feita com o estatismo pastoral que aquele autor atribuiria a Weber, vinculando-o a preocupações de Hegel - quando na verdade, se relação há, é muito mais aquela que surge das páginas da Fenomenologia do espírito, acerca das relações entre o senhor e o escravo, sem, contudo, uma consciência que transcenda a luta imediata e a dominação entre os sujeitos. Esta diria respeito, em Weber, à "orientação básica", recíproca, na vida cotidiana, ao passo que a multiplicidade dos valores termina reduzida precisamente pelo poder de mando dos dominantes, que, destarte, obrigam, ao construir esquemas de legitimação, os dominados a abrir mão da busca de "valores alternativos". Além disso, o quadro administrativo surge, aqui, com muito menos autonomia que nas leituras usuais de Weber, cumprindo, sobretudo, uma relação de mediação (não dialética, deve-se assinalar, logo externa aos que vincula) entre dominantes e dominados (ibidem:119-123). É verdade que Cohn tende a restringir sua análise à modernidade e à "dominação racional-legal", e talvez à "carismática" de modo implícito, deixando um tanto a descoberto a “dominação tradicional" (ver Weber, [1921-22] 1994-99). É verdade também que muito do que Cohn traz à baila não pode ser encontrado, como ele mesmo chega a observar, textualmente nos intricados e sutis escritos de Weber. Mas sua argumentação é mais do que legítima: ela permite a compreensão do significado de certos aspectos do pensamento weberiano que com frequência permanecem obscurecidos por questões metodológicas menores, ao passo que estas são aqui integradas em um plano superior, e, portanto, mais esclarecedor ${ }^{3}$, remetendo-nos, enfim, ao plano ético. Pois é aqui precisamente que a visão "realista" e "desencantada" de Weber se encontra, e de certa forma se opõe aos valores mais caros ao próprio sociólogo alemão-autonomia e 
liberdade, como expressão de um liberalismo humanista deslocado em um mundo de crescente dominação racionalizada. Crítica e resignação derivariam dessa desafortunada conjunção, pois se Weber recusa axiologicamente os contornos essenciais de seu mundo, não crê ser possível efetivamente transformá-lo. Assim, o que almejava era conhecê-lo ao máximo para saber o quanto podia "suportar" (Cohn, 1979:138ss).

Como vimos, então, aflora nessa discussão a temática do pluralismo que seria crucial na modernidade e dificilmente se esclarece bem diretamente nos textos de Weber em sua trágica conjunção com a homogeneizante dominação racional-legal -, resolvida precisamente por esse processo em que poder e racionalização se conjugam e eliminam, ao menos em grande medida, a promessa moderna de liberdade. Anteriormente, porém, esse tema já havia intrigado Cohn, no curso de sua análise das teorias da comunicação. Mas àquela altura não vê efetivamente muito avanço na concepção pluralista que encontra na sociologia norte-americana, pois a considera meramente descritiva, sem capacidade explicativa, e até mesmo compatível com argumentos relativos à sociedade de massas. Os princípios organizadores da vida social permanecem na penumbra, com ao todo social sendo imputado fraco potencial democrático (Cohn, 1973:78, 83, 94-97, 109ss). Mas, nem teórica, nem normativamente, a questão avança muito a esta altura. Seria preciso esperar a virada do milênio e uma nova configuração da modernidade para que isso acontecesse.

Enfim, vale notar que Cohn a esta altura muito claramente articula sua teoria a partir de uma forte noção de subjetividade. Se não a elabora no plano coletivo, isto é, para além do plano individual, ainda que o integrando, ela está presente com toda força exatamente na centralidade que atribui ao conceito de dominação, sem prejuízo de outras dimensões, tradicionalmente ditas sistêmicas ou estruturais. Segundo ele mesmo, isso lhe valeu uma, a meu ver, estranha acusação de weberianismo da parte de Florestan Fernandes por ocasião da defesa de sua tese de mestrado (Cohn, 2006:116-117). Mas Cohn, cuja leitura de Adorno é tão forte, e na qual se distancia da ideia mais antiga deste autor sobre uma suposta "sociedade administrada" (Cohn, 1973:126), para, em vez disso, emprestar ênfase aos conceitos de classe e dominação, poderia ter perfeitamente rebatido aquele comentário um tanto torto. Inspirando-se em Adorno, seria com certeza capaz de demonstrar que a teoria crítica pode ser entendida de modo estruturalista, ou mesmo funcionalista, sem que essa seja a única leitura possível, não 
sendo, a rigor, sequer a mais adequada (ver, por exemplo, Anderson, 1984). De resto, assim como era o caso para a esfera pública e a comunicação, onde subjetividade, dominação e conflito se destacavam, com referência à obra de Weber é o conjunto da vida social que aparece atravessado pelo conflito e estruturado pela dominação, ambos assentando-se sobre uma subjetividade que Cohn não chega bem a definir. Se isso é verdadeiro para a fase dos escritos que acabamos de analisar, manter-se-ia nas décadas seguintes, com amiúde mais economia de expressão e alusões, porém por vezes com mais precisão na forma de desenharem-se as questões.

\section{O CENÁRIO DESOLADO DA MODERNIDADE CONTEMPORÂNEA}

Uma das preocupações mais caras a Adorno, e que se expressa inúmeras vezes em seus textos, inclusive nas discussões acerca do "logocentrismo" da modernidade e de sua expressão direta no antissemitismo, na Dialética do Esclarecimento (Adorno e Horkheimer, [1944] 1985), referia-se ao "particular" (das Besondere) em sua multiplicidade e absoluta dignidade humana - e inclusive no que tange à natureza. Tratava-se de denunciar uma razão que se convertera em mito e dominação, e cuja mimese fixava-se em um ponto que, ao homogeneizar o mundo, obscurecia antes que iluminava. Isso era feito em nome de uma razão mais plena, capaz de "[...] achegar-se reflexivamente ao diferente" (Cohn, 1997:11). Isso culminaria em Adorno, na completa e delicada articulação filosófica de sua "dialética negativa", em que recusava a síntese de modo a escapar à tirania de uma razão que recusava tudo que lhe fosse diferente e teimasse em permanecer irredutível, subsumindo-o pela transformação ou o negando e destruindo, como fez com os judeus. Mas obviamente essa negatividade da dialética adorniana apresentava-se em defesa da liberdade, da solidariedade e de um universo mais amplo e aberto à diversidade, ainda que o filósofo se recusasse, por seu turno, a dar conteúdo específico a essa utopia, que se apresenta então como uma razão que não pode pronunciar seu nome (Adorno, [1966] 1980:213-214, 261-262). Essa temática, embora presente, não se manifestava, como já observado, com centralidade nos textos de Cohn dos anos 1970 e seguintes. A partir do novo século ela se torna fundamental, conquanto a referência explícita e central aí, pinceladas à parte, não seja tanto Adorno. Sem dúvida, Cohn (1990, 1998a) sugere que os temas relativos ao conceito de indústria cultural, tais como dominação e homogeneização, retêm validade indubitável, não obstante a necessidade de pesquisa empírica reiterada para sustentar o ponto, no mundo 
pós-fordista, pós-produção em massa, customizado, ou no qual a "reflexividade" dos sujeitos se exerceria com menores peias (segundo autores como Beck e Giddens, por exemplo). O conceito de Adorno teria muito a nos dizer, a despeito da aparente pluralidade dos produtos e do consumo culturais, assim como de uma suposta liberdade dos indivíduos nos dias de hoje. O peso do argumento é, porém, posto alhures.

Em um artigo sobre Simmel e Luhmann - novos personagens em sua discografia, cada qual com sua "linguagem fin-de-siècle" na teoria social -, Cohn (1998c) iria dar atenção ao que chamou de "diferenças finas" segundo o enfoque de ambos, que evidentemente trilham caminhos bastante distintos. O texto é quase enigmático e, lido isoladamente, se mostra uma pérola de análise ela também fina, sem que, contudo, fique efetivamente claro o significado da discussão, para além daquilo que é sugerido de modo sutil em suas páginas. Na verdade, inserido em uma discussão mais ampla, que Cohn avança alhures de uma forma, aliás, pouco usual em seu estilo, isto é, altamente incisiva, o texto assume outra dimensão. A chave aí é muito mais Luhmann que Simmel, embora o tema seja comum a ambos. No caso do primeiro, as "aproximações" e "afastamentos" no "fluxo das experiências humanas", da "vida", vão no sentido de gerar "reciprocidades de ações" e criar "laços" de diversas naturezas em sociedades altamente complexas; não há nele, contudo, solução normativa à maneira de Parsons que resolva definitivamente esse problema, nem racionalidade de escolhas em sentido utilitário para dar conta da questão, mantendo-se ela, até certo ponto ao menos, no terreno da espontaneidade e da fugacidade da ação. O dinheiro lança pontes formais entre as pessoas e as formas introduzem padrões que talvez se imponham aos atores e engendrem tensão em relação àquela espontaneidade, mas Cohn sugere essas questões mais como interrogação que como resposta para os pontos que vai levantando.

No caso de Luhmann, o tema é mais agudo. Trata-se de autor ao qual Cohn (2006:123) empresta, hoje, especial importância, não porque tenha de fato empatia com sua obra, afirma, e muito menos porque adote realmente seus conceitos e soluções, mas por colocar problemas e surgir, lanço a ideia como hipótese, quase que como um sintoma de nossa época, cínica e sedutora, verdadeiro terreno de barbárie (ao passo que Habermas representa uma possibilidade de futuro). Cohn (1998) recapitula então os principais elementos do sistema teórico luhmanniano e daí segue para tecer considerações que fornecem, em outro contexto, 
sustentação a uma incisiva visão crítica do mundo contemporâneo. Sistema e ambiente, complexidade, contingência e diferença, os sistemas como "entidades operacionais" autorreferidas e "autopoiéticas", são os eixos daquela construção teórica, que no texto em tela nos levam a uma questão específica, que ademais permite uma ponte imediata com Simmel: trata-se das fronteiras sociais. Estas se criam a partir do que Parsons definira como a "dupla contingência" da ação, resolvida por ele mediante a abóbada normativa que impediria que a vida social degenerasse em mal-entendido permanente ou, pior, em guerra contínua. É na solução dessa questão que, para Luhmann, argumenta Cohn, surgem os sistemas, não por meio daquela saída normativa, mas ao criar fronteiras, ao organizar suas diferenças com o meio através de suas próprias formas, suas operações de autocriação, que são ao mesmo tempo operações de seleção, que devem ser reiteradamente realizadas, em condições de contingência permanente. Com isso se definem para o sistema aqueles elementos que lhe são relevantes, o que permite a comunicação dentro dele próprio, ainda que toda a questão do "acoplamento estrutural" (a meu ver, um dos pontos de maior fragilidade na construção de Luhmann) de um sistema com outro (por exemplo, os sociais e os psíquicos) seja tema adicional que aflora ao longo da discussão, sem que a experiência dos sujeitos interesse, por outro lado, a Luhmann.

Curiosamente, fechamos, no plano teórico geral, provisoriamente, uma trajetória: comunicação e diferença, tema explícito do início da carreira de Cohn, por um lado, questão subjacente em sua leitura dos frankfurtianos, por outro, se encontram a esta altura. Mas, mais importante que isto, é o resultado prático que ele desdobra dessas leituras que nada têm de casuais ou desinteressadas, com certa torção operando-se em sua perspectiva. Vejamos:

[...] até uma fase avançada do século $\mathrm{XX}$ a referência paradigmática consistia na associação entre organização e expansão. Vale dizer, estavam em jogo processos expansivos de diferenciação interna das sociedades, tanto pela ótica dos elementos de sistemas quanto do prisma da constituição de atores. Na virada do século, contudo, rompe-se essa associação entre organização e expansão, pela perda de substância do segundo termo - desgaste este que envolve uma separação mais funda, entre $e x$ pansão e acumulação, que antes andavam juntas. A referência à organização segue sendo central, mas tende a girar no vazio quando não se encontra o termo que possa substituir o de expansão (ou seu associado di- 
reto, acumulação). Tanto quanto consigo ver, esse termo já se mostra com nitidez: trata-se de seleção. A ideia, aqui, é de que nas condições que se vão desenhando contemporaneamente, o princípio da seleção cumpre papel correspondente ao da acumulação na fase que se vai fechando. É esse princípio que promete dar conta de uma condição histórica em que sistemas altamente complexos e, portanto, muito avançados em termos de organização vão constituindo uma dinâmica em que a expansão, desvinculada da acumulação, se dá pela eliminação de partes pela borda a fora mais do que pela incorporação de elementos e processos (embora esta também ocorra). (Cohn, 2003:134; ênfases no original)

Ou seja, trata-se, agora, de fazer face à "aceleração dos processos de exclusão, e não mais de inclusão" - em outras palavras, de criação de fronteiras - nos quadros do que se poderia chamar de um novo "umbral civilizatório" (ibidem:133, 135). Num ataque implícito, mas forte a Elias, ele segue em frente e observa que não se pode separar "civilização" e "cultura". Isto enfraquece a crítica, pois demandaria a cultura (particular) para corrigir a civilização (universal), ao passo que ele quer pensar a civilização (e assim a cultura) como uma "formação", que inclui vida civil, liberdade, repouso e paz, ou seja, aquilo que movia os mestres das ciências sociais. A barbárie tem inclusive, dialeticamente, seu momento de verdade como limite concreto da civilização cuja vocação é universal - ao sublinhar as diferenças entre as pessoas e coletividades (aí sim, em uma leitura mais próxima dos frankfurtianos). Mas, em grande medida, quem anima o argumento e a ele subjaz é, obviamente, Luhmann, ao permitir pensar que sistemas complexos, em particular as organizações, selecionam seus próprios elementos e se lixam para o restante do mundo. É claro que a apropriação de Luhmann é, aqui, a penas parcial: o intuito de Cohn é "francamente normativo" e crítico, antirreificador, o oposto do quietismo quase cínico de Luhmann, e, neste sentido, mais próximo inclusive de Simmel, ao apostar na contrapartida de uma subjetividade densa. A postura aqui em tela implica a recusa das peculiaridades absolutas e soltas, quando impera, na verdade, a barbárie, cujo signo é um respeito frouxo que desliza prontamente rumo à indiferença, aquela mesma que Luhmann identificara, por meio da criação da diferença por parte dos sistemas em relação a seu meio, como fundamental para o fechamento operacional dos sistemas autorregulados, as grandes organizações a que se refere Cohn nessas passagens ${ }^{4}$. Isto seria uma forma específica e típica do funcionamento do capitalismo contemporâneo, em que um número 
restrito de agentes econômicos, atuando em um mundo "hipercomplexo", toma decisões e impõe-se aguda mobilidade, gerando enormes impactos que usualmente eles mesmos podem tomar como "irrelevantes para seus objetivos circunstanciais". Estaríamos assim muito longe da ideia de mercado concorrencial em sentido clássico, em que à ação do indivíduo correspondia uma responsabilidade forte, sem o que a própria ideia de organização perderia sentido. Grupos sociais enormes podem ser assim excluídos, não porque sejam incovenientes (como, pode-se supor, eram os judeus na discussão de Adorno e Horkheimer), mas por serem irrelevantes. A indiferença estrutural é a expressão concentrada dessa situação e a democracia mínima sua contrapartida política, como forma de evitarem-se ruídos para aqueles processos de seleção (ibidem:137-145; 2006a).

Em outras palavras, operou-se uma transmudação violenta e de largo alcance. Podemos sugerir que se Marx enfrentou o mundo da modernidade liberal em expansão e sobre os frankfurtianos desabou uma formação em que grandes organizações - como o Estado e as corporações econômicas de tipo fordista - buscavam controlar e homogeneizar o mundo, hoje deparamo-nos com outra fase da modernidade, a terceira, em que os processos de dominação, exclusão e seleção têm lugar em um mundo cuja heterogeneidade não importa mais superar, e no qual redes sociais podem desempenhar papéis virtuosos, bem como mostrarem-se, por seu exclusivismo, extremamente perversas. Trata-se, sim, para as organizações, de instrumentalizar essa heterogeneidade no sentido do lucro e do poder, não obstante pias declarações de responsabilidade corporativa ou algo do gênero (cf. Domingues, 2002). Não que a América Latina não conhecesse processos deste tipo desde há muito, uma vez que o mercado capitalista e o Estado jamais lograram uma incorporação homogeneizadora das populações do subcontinente, como a polêmica, por exemplo, sobre a "marginalidade", não obstante suas debilidades teóricas, claramente evidenciava (ver Nun, 2001). Ao menos, contudo, o horizonte normativo da modernidade, aqui como no resto do mundo, tomava essa situação como provisória e formalmente projetava a sua superação, por meio de uma inclusão universal, processos de dominação e homogeneização não obstante. A nova configuração da modernidade já não se importa com isso e é a ela que a crítica de Cohn fortemente se dirige.

Se o tom que se segue à crítica é normativo, como assinalado acima, cabe pensar nos antídotos contra essa situação. É curioso que Cohn em 
certos momentos assimile como sua uma perspectiva resignada, a qual, tal qual Weber, reconheceria a nossa incapacidade de transformar um mundo em que impera a barbárie, sendo este reconhecimento a base mesma para uma atitude de onde decolaria a crítica (Cohn, 2006:121, 132). Mas aqui não é disto que se trata, não resulta daquele diagnóstico do presente uma aceitação, resignada, como a do velho Tocqueville, que se retirou da cena política ao reconhecer que sua posição já não tinha lugar na história (idem, 2000b). Nosso sociólogo é enfático ao demandar tanto um aprofundamento da democracia que se contraponha à seletividade e à exclusão, quanto uma ênfase na responsabilidade e na reivindicação da reflexividade como "exigência normativa [...] ligada ao cuidado com a dimensão civilizada da vida social" (idem, 2003:136, 144). Isto deveria, ademais, se calcar em uma concepção cívica da cidadania, capaz de combinar universalismo e contexto (idem, 2006a). Não se aceitam deste modo nem as diferenças por si - a mediação entre o universal e o particular continuando a ser tão importante como antes -, nem o mercado, ademais estruturado em classes sob o capitalismo, como senhor da civilidade e dos laços sociais (idem, 1995). Não por acaso ele voltou a Durkheim e acentuou a importância, implicitamente contra o economicismo neoliberal, de seu individualismo moral, bem como da necessidade de auto-organização da sociedade que aquele autor apontara em sua teoria das corporações, malgrado as deficiências graves que sua proposta continha (idem, 1999).

Ou seja, nem tudo está perdido, embora, como reconhece em outras ocasiões, as coisas não estejam nada fáceis e já não possamos mais confiar numa razão que os dias alegres da juventude de Marx e Lukács podiam ainda imaginar como nos oferecendo notas promissórias que em algum futuro, a curto ou longo prazos, seriam forçosamente descontadas (idem, 1995, 1998). A isso aduz a demanda de uma nova teoria da "experiência social" (tema antigo, conquanto igualmente implícito, em seus textos) para dar conta do mundo contemporâneo (idem, 2003:135). A dominação, que perdura em suas várias formas, e a indiferença, estrutural, nos apresentam uma paisagem tão desolada quanto a que se pôs a Adorno, Horkheimer e Marcuse. Não nos condenam, todavia, à inação e a uma resignação sem lugar para uma crítica que reivindique a responsabilidade civil pelo estado do mundo. Há, sim, espaço para um pensamento sociológico ágil e inconformista, comprometido com nosso tempo e a transformação da sociedade. 


\section{PALAVRAS FINAIS}

Fazer teoria na periferia não é fácil, fazer teoria crítica de maneira frouxa talvez seja até mais fácil nela, em função das calamidades permanentes que a acometem, mas não se o rigor teórico é aquilo que se persegue. Fazer teoria sem ter de evocar sempre seu país, o Brasil, a Argentina ou a Venezuela, para ficarmos em nossas vizinhanças subcontinentais, é ainda mais difícil fora do centro. Trata-se, evidentemente, de uma introjeção coletiva de uma concepção que nos reserva lugar secundário na divisão internacional do trabalho intelectual, para além dos problemas que, em termos de identidade, essa posição periférica já nos coloca (o que não quer dizer que não haja o risco de reificação de categorias forjadas em outras paragens, via uma falsa universalização, o que nosso autor evita, aliás, galhardamente). A atual geração de cientistas sociais brasileiros que se ocupa de teoria social e de teoria crítica deve, neste sentido, imensamente a Gabriel Cohn, que desbravou entre nós um terreno que apenas hoje começa a se fazer de fato mais legítimo.

Como isto não bastasse, como este texto procurou demonstrar, um pequeno tesouro se encontra em seus trabalhos, sempre eruditos, sutis e profundamente originais, cuja expressão em edições antigas ou dispersão em livros e periódicos amiúde de raro acesso - com a exceção de seu livro sobre Weber - dificultam uma visão integrada de suas ideias. Procurei aqui articulá-las por meio de dois eixos, um mais antigo, vinculado à noção de dominação, que, todavia, perdura até hoje, outro mais recente e que responde, de maneira sofisticada no plano teórico, aos duros desenvolvimentos da realidade empírica, remetendo à temática da "indiferença estrutural". Certamente os alunos de Cohn na USP têm uma possibilidade maior de acesso às suas ideias, as quais são, reza a lenda, neste caso sem dúvida fidedigna, laboriosamente articuladas em seus cursos e seminários, cuja expressão escrita e mais pública vai se fazendo nas últimas décadas nos ensaios sugestivos que de maneira parcimoniosa entrega para publicação.

Apenas uma vez, afora seminários, sobretudo organizados pelo Grupo de Trabalho de Teoria Social da Associação Nacional de Pós-Graduação e Pesquisa em Ciências Sociais (Anpocs), do qual Cohn sempre foi participante ativo e inspiração fundamental, tive a oportunidade de ver como essa atividade docente se realiza. Foi, em meados dos anos 1990, quando, estreando no cenário nacional como teórico social, fui 
convidado a compartilhar um curso com ele em atividades da Sociedade Brasileira de Sociologia, em São Paulo. Cohn ministrou a primeira aula, sobre Habermas e Luhmann, se não me trai a memória. Ao final de uma brilhantíssima exposição, em que conhecimento e raciocínio articulado a céu aberto se somavam, numa rara combinação de didática e exploração intelectual ao vivo, foi ovacionado pelos estudantes. Ao se despedir de mim sussurrou: "quero ver você amanhã". Obviamente, passei a noite em claro, preparando minha aula, sobre as correntes sociológicas contemporâneas que versavam sobre a evolução e a história. Como me saí, apesar do elogio que me ofereceu posteriormente, não sei ao certo. Mas levei comigo daquele dia uma indelével imagem de Gabriel Cohn, marcada por rigor e criatividade, compromisso e generosidade intelectual.

(Recebido para publicação em junho de 2011) (Aprovado para publicação em setembro de 2011)

(Versão definitiva em agosto de 2011) 


\section{NOTAS}

1. Para me restringir ao trabalho conjunto daqueles autores, observo somente que Cohn curiosamente escolhe passar por cima das duras passagens sobre a "cultura de massa" que se encontram na Dialética do Esclarecimento (Adorno e Horkheimer, [1944] 1985). Não se tratava, é evidente, de desconhecimento. Seria uma questão de estratégia discursiva?

2. Uma seleção básica dos textos de Adorno, que toca em aspectos importantes dessa discussão, foi realizada em seguida por Cohn (1986).

3. Trata-se, a meu ver, de longe, da melhor análise da metodologia weberiana e de sua estratégia de tipos ideais. Para uma recente, mas mais tradicional abordagem, ver Kalberg (1994). Utilizei-me da leitura do caráter "genético" dos tipos ideais por Cohn (1979, em especial cap. 5) para estudar a concepção de cidade em Weber e tematizar sua concepção de liberdade em Domingues ([2000] 2003).

4. Em sua obra conclusiva, Luhmann (1998, vol. 2: esp. 829-830, 837-838, 846-847) observa que como "forma sistêmica" a pertença à organização delimita aquilo que a ela "primariamente interessa", buscando-se coerência e integração internamente. E, embora organizações consistam no único tipo de sistema que pode se comunicar com seu meio, tendo como garantia de sua autorreferência e autopoiesis sua hierarquia interna, aquele meio é observável, evidentemente, de acordo com as regras do próprio sistema, de maneira altamente "seletiva", portanto. Contra expectativas aristotélicas e romantizadas de um centramento (cívico-político) da sociedade, ele afirma que nenhuma organização representa, em sua totalidade, o sistema - evolutivamente diferenciado de maneira extrema - e que só por si é cada uma delas "responsável", ainda que "efeitos de agregação" sobre o meio possam ter impactos de retorno sobre elas. Ademais "inclusão" depende de "exclusão"; não são equacionáveis mediante o discurso dos direitos (Luhmann, 1998, vol. 2: 618ss). A circularidade do raciocínio se mostra, como de hábito, insuperável. Os limites para enfrentar os temas postos por Cohn, se Luhmann chegasse a considerá-los problemáticos, seriam evidentemente enormes. 


\section{REFERÊNCIAS BIBLIOGRÁFICAS}

ADORNO, Theodor W. ([1966] 1980), Negative Dialektik. Frankfurt am Main, Suhrkamp. e HORKHEIMER, Max. ([1944] 1985), Dialética do Esclarecimento. Rio de Janeiro, Zahar.

ANDERSON, Perry. (1984), A Crise da Crise do Marxismo: Introdução a um Debate Contemporâneo. São Paulo, Brasiliense.

COHN, Gabriel. (1968a), “A Sociologia e a Arte da Controvérsia”. Revista Civilização Brasileira, no 19-20.

_ (1968b), Petróleo e Nacionalismo. São Paulo, Difel.

. (1973), Sociologia da Comunicação. Teoria e Ideologia. São Paulo, Pioneira.

. (1978), Crítica e Resignação. Fundamentos da Sociologia de Max Weber. São Paulo, T. A.

Queiroz.

. (1986), “O Ecletismo Bem-Temperado", in M. d'A. Incao (org.), O Saber Militante. Ensaios sobre Florestan Fernandes. São Paulo, Editora Unesp e Paz e Terra.

. (1987), “Weber, Habermas, o la Búsqueda por la Racionalidad en la Acción Política", in N. Lechner (org.), ¿Que es el Realismo en Política? Buenos Aires, Catálogos.

. (1990), “Difícil Reconciliação: Adorno e a Dialética da Cultura”. Lua Nova, no 20.

. (1993), "A Teoria da Ação em Habermas", in M. C. B. de Carvalho (org.), Teorias da Ação em Debate. São Paulo, Cortez.

. (1995), "Razão e História", in T. Vigevani (org.), Liberalismo e Socialismo, Velhos e Novos Paradigmas. São Paulo, Editora Unesp.

. (1997), "Esclarecimento e Ofuscação: Adorno e Horkheimer Hoje". Lua Nova, no 43.

(1998a), "A Atualidade do Conceito de Indústria Cultural", in A. da S. Moreira (org.), Sociedade Global. Cultura e Religião. Petrópolis, Vozes.

. (1998b), “O Travo Amargo da História”. Estudos Avançados, vol. 31.

. (1998c), "As Diferenças Finas: De Simmel a Luhmann". Revista Brasileira de Ciências Sociais, vol. 13.

. (1999), "Individualidade e Cidadania num Mundo Dividido". Perspectivas, vol. 22.

(2000a), "Perfis em Teoria Social: Tocqueville e Weber, Duas Vocações", in L. Avritzer e J. M. Domingues (orgs.), Teoria Social e Modernidade no Brasil. Belo Horizonte, Editora UFMG.

. (2000b), “Tocqueville y la Pasión Bien Comprendida”, in A. Boron (org.), La Filosofía Política Moderna. De Hobbes a Marx. Buenos Aires, CLACSO.

. (2003), “A Sociologia e o Novo Padrão Civilizatório" , in C. Barreira (org.), A Sociologia no Tempo. São Paulo, Cortez. 
. (2006a), “Civilização, Cidadania e Civismo: A Teoria Política frente aos Novos Desafios", in A. Boron (org.), Filosofia Política Contemporânea. Controvérsias sobre Cidadania, República e Democracia. Buenos Aires, CLACSO.

. (2006b), “Gabriel Cohn”. Entrevista em Elide Rugai Bastos et al., Conversas com Sociólogos Brasileiros. São Paulo, Editora 34.

DOMINGUES, José Maurício. ([2000] 2003), “A Cidade. Racionalização e Liberdade em Max Weber", in Do Ocidente à Modernidade. Intelectuais e Mudança Social. Rio de Janeiro, Civilização Brasileira.

. (2002), Interpretando a Modernidade. Imaginário e Instituições. Rio de Janeiro, FGV Editora.

EDER, Klaus. (1985), Geschichte als Lernprozess? Frankfurt am Main, Suhrkamp.

. (2006), "Making Sense of the Public Sphere", in G. Delanty (org.), Handbook of Contemporary European Social Theory. London e New York, Routledge.

FERNANDES, Florestan. ([1958] 1977), “O Padrão de Trabalho Científico dos Sociológicos Brasileiros", in F. Fernandes, A Sociologia no Brasil. Contribuição para o Estudo de sua Formação e Desenvolvimento. Petrópolis, Vozes.

FLEISCHMANN, Eugène. ([1964] 1977), "Weber e Nietzsche”, in G. Cohn (org.), Sociologia: Para Ler os Clássicos. São Paulo, Livros Técnicos e Científicos.

HABERMAS, Jürgen. ([1962] 1984), Mudança Estrutural da Esfera Pública. Rio de Janeiro, Tempo Brasileiro.

(1992), Faktzität und Geltung. Frankfurt am Main, Suhrkamp.

KALBERG, Stephen. (1994), Max Weber's Comparative-Historical Sociology. Chicago, University of Chicago Press.

LUHMANN, Niklas. (1998), Die Gesellsechaft der Gesellschaft. Frankfurt am Main, Suhrkamp, 2 vols.

NUN, José. (2001), Marginalidad y Exclusión Social. México, Fondo de Cultura Económica.

WAIZBORT, Leopoldo (org.). ([1998] 2008), A Ousadia Crítica. Ensaios para Gabriel Cohn. São Paulo, Azougue.

WEBER, Max. ([1921-22] 1994-99), Economia e Sociedade. Brasília, Editora Universidade de Brasília, vols. 1-2.

ZEA, Leopoldo. (1976), El Pensamiento Latinoamericano. Barcelona, Ariel. 


\section{ABSTRACT \\ Domination and Indifference in the Critical Theory of Gabriel Cohn}

This article reconstructs the theoretical trajectory of Gabriel Cohn, whose work can be divided broadly into two phases. In the first, particularly under the influence of Adorno and Weber, modernity is viewed from the angle of domination and a tendency towards the construction of oppressively inclusive systems. In the second, maintaining these fundamentals, the issues of "pluralism" and indifference (particularly with a critical reading of Luhmann) are perceived as shaping a new pattern of civilization. Cohn thus proves to be a fundamental theoretical reference for understanding modernity in both its initial and contemporary phases.

Key words: Gabriel Cohn; critical theory; modernity

\section{RÉSUMÉ}

\section{Domination et Indifférence dans la Théorie Critique de Gabriel Cohn}

Dans cet article, on reconstitue la trajectoire théorique de Gabriel Cohn, dont l'oeuvre peut être partagée grosso modo en deux phases. Dans la première, sous l'influence d'Adorno et de Weber en particulier, la modernité est vue sous l'angle de la domination et d'une tendance à la construction de systèmes inclusifs par l'oppression. Dans la seconde, une fois conservés ces fondements, la notion de "pluralisme" et d'indifférence, à partir d'une lecture critique de l'oeuvre de Luhmann surtout, est envisagée comme formant un nouveau modèle de civilisation. Cohn devient ainsi une référence fondamentale du point de vue théorique dans la compréhension de la modernité à ses débuts et dans sa phase actuelle.

Mots-clés: Gabriel Cohn; théorie critique; modernité 